\title{
GFAP canonical transcript may not be suitable for the diagnosis of adult-onset Alexander disease
}

\author{
Filippo Pinto e Vairo ${ }^{1,2,3}$, Nicole Bertsch ${ }^{3}$, Eric W. Klee ${ }^{1,2,3,4^{*}}$ and Ralitza H. Gavrilova ${ }^{1,3,5}$
}

Keywords: Adult-onset Alexander disease, Sanger sequencing, Alternative transcripts, GFAP

To the editor,

Alexander disease (AD) is an autosomal dominant progressive leukoencephalopathy caused by heterozygous mutations in the glial fibrillary acidic protein (GFAP) gene. Onset of symptoms can range from infancy to adulthood, with the infantile form being most common and the adult onset form accounting for one third of cases [4]. A clinical diagnosis is typically confirmed via sequencing of the GFAP gene, as $98 \%$ of the individuals have detectable single nucleotide or small indels pathogenic variants. Here we highlight the emerging importance of testing an exon only expressed in an alternative GFAP transcript, which has recently been shown to harbor pathogenic variation found in lateronset patient presentations. A brief survey of clinical testing laboratories reveals that not all include this exon in the reportable range of GFAP testing and consequently fail to reveal the correct genetic diagnosis. This point is highlighted in a 43-year-old male patient was referred to Clinical Genomics for evaluation of hereditary hemorrhagic telangiectasia (HTT) based on positive family history and a variant of uncertain significance (VUS) in ACVRL1 (c.106T > C; p.Cys36Arg). In addition, he presented with a family history of an unidentified leukodystrophy in mother and maternal uncle, and a potential AD diagnosis based on the characteristic distribution of Rosenthal fibers in uncle's autopsy and mother's neurological symptoms. His mother was 67 years old and had history for about four years of progressive worsening gait, spasticity, and slurred speech. MRI revealed leukodystrophy. The patient was asymptomatic with a normal neurological examination (no gait abnormality, abnormal posture, dysarthria, or other symptoms related to AD) but a brain MRI demonstrated findings previously described in adult-onset $\mathrm{AD}$ (Fig. 1) [3]. GFAP sequencing (NM_002055.3 transcript) done at a CLIA laboratory revealed no pathogenic variants. Additional genetic evaluation for adult-onset leukoencephalopathies was also negative. Subsequent research whole exome sequencing (WES) detected a pathogenic variant in a deep intronic region of the canonical transcript (c.1171 + 472G > A) as well as in exon 7 of an alternative transcript (NM_001131019.2(GFAP):c.1289G > A; p.(Arg430His)). This variant has been previously reported in two affected individuals with clinical and MRI findings of AD and a variant in HDAC6, a possible modifier gene [2]. Noteworthy, we did not find variants in HDAC6 or other known modifiers in our patient. The GFAP variant is present in 2 of 245,904 alleles in gnomAD [1]. Since the disease is thought to be fully penetrant, there may be two other presently asymptomatic/oligosymptomatic individuals who remain undiagnosed. Therefore, when the diagnosis is

* Correspondence: klee.eric@mayo.edu

${ }^{1}$ Center for Individualized Medicine, Mayo Clinic, Harwick 3, 200 First Street SW, Rochester, MN 55905, USA

2Department of Health Sciences Research, Mayo Clinic, Rochester, MN, USA

Full list of author information is available at the end of the article 


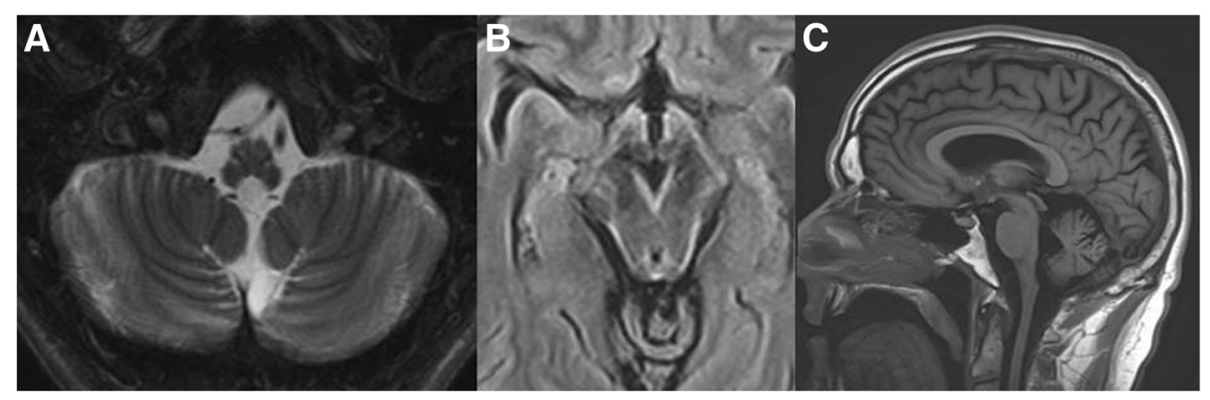

Fig. 1 a Severe atrophic changes of the medulla including the inferior olivary nuclei. Moderate cerebellar atrophy. b Linear symmetric abnormal T2 signal predominantly along the anteriolateral aspect of the medulla and a thin zone of abnormal T2 signal about the periphery of the midbrain. c Sagittal view showing atrophy of the brainstem and upper cervical cord. No changes were noted in the subcortical regions

clinically suspected, alternative molecular analysis may be warranted to detect changes in all relevant transcripts. Moreover, our patient is the third reported case with the same causative variant in an alternative GFAP exon, making this variant a recurrent cause of adult-onset AD. We believe that the available clinical genetic testing for $\mathrm{AD}$ should be revisited and include this alternate exon.

\section{Acknowledgments}

The authors are grateful to the patient reported here for giving them permission to share his data.

\section{Funding}

This work was supported by the Mayo Clinic Center for Individualized Medicine (CIM), the Investigative and Functional Genomics Program, and the William O. Lund, Jr. and Natalie C. Lund Charitable Foundation.

\section{Availability of data and materials}

Not applicable.

\section{Authors' contributions}

FPV: acquisition, analysis, interpretation of data and writing. NB: acquisition of data and critical revision of the manuscript for intellectual content. EK: study supervision and critical revision of the manuscript for intellectual content. RHG: acquisition of data, supervision, and critical revision of the manuscript for intellectual content. All authors read and approved the final manuscript.

\section{Ethics approval and consent to participate}

This study was performed in accordance with the guidelines of Mayo Clinic Institutional Review Board (12-009346) and ethical standards laid down in the 1964 Declaration of Helsinki.

\section{Consent for publication}

The patient has consented for publication.

\section{Competing interests}

The authors declare that they have no competing interests.

\section{Publisher's Note}

Springer Nature remains neutral with regard to jurisdictional claims in published maps and institutional affiliations.

\section{Author details}

${ }^{1}$ Center for Individualized Medicine, Mayo Clinic, Harwick 3, 200 First Street SW, Rochester, MN 55905, USA. ²Department of Health Sciences Research, Mayo Clinic, Rochester, MN, USA. ${ }^{3}$ Department of Clinical Genomics, Mayo Clinic, Rochester, MN, USA. ${ }^{4}$ Department of Biomedical Informatics, Mayo Clinic, Rochester, MN, USA. ${ }^{5}$ Department of Neurology, Mayo Clinic, Rochester, MN, USA.
Received: 20 September 2018 Accepted: 11 October 2018 Published online: 24 October 2018

\section{References}

1. Let et al. Analysis of protein-coding genetic variation in 60,706 humans. Nature. 2016:536(7616):285-91. https://doi.org/10.1038/nature19057.

2. Melchionda L, Fang M, Wang $H$ et al (2013) Adult-onset Alexander disease, associated with a mutation in an alternative GFAP transcript, may be phenotypically modulated by a non-neutral HDAC6 variant. Orphanet J Rare Dis 8:66

3. Schmidt S, Wattjes MP, Gerding WM, van der Knaap M (2011) Late onset Alexander's disease presenting as cerebellar ataxia associated with a novel mutation in the GFAP gene. J Neurol 258:938-940

4. Srivastava S, Naidu S. Alexander Disease. In: Adam MP, Ardinger HH, Pagon RA, et al. editors. GeneReviews((R)). Seattle 1993.
Ready to submit your research? Choose BMC and benefit from:

- fast, convenient online submission

- thorough peer review by experienced researchers in your field

- rapid publication on acceptance

- support for research data, including large and complex data types

- gold Open Access which fosters wider collaboration and increased citations

- maximum visibility for your research: over $100 \mathrm{M}$ website views per year

At BMC, research is always in progress.

Learn more biomedcentral.com/submissions 